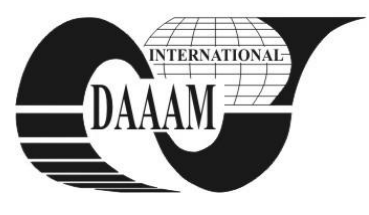

Annals of DAAAM for 2012 \& Proceedings of the 23rd International DAAAM Symposium, Volume 23, No.1, ISSN 2304-1382 ISBN 978-3-901509-91-9, CDROM version, Ed. B. Katalinic, Published by DAAAM International, Vienna, Austria, EU, 2012 Make Harmony between Technology and Nature, and Your Mind will Fly Free as a Bird Annals \& Proceedings of DAAAM International 2012

\title{
INDUSTRIAL SENSORS TESTING
}

\section{ENCIU, G[eorge]; NICOLESCU, A[drian] F[lorin]; DOBRESCU, T[iberiu] G[abriel] \& POPESCU, C[onstantin] - A[drian]}

\begin{abstract}
In automated industrial processes, sensory systems interface is the only way of working environment and control system. Therefore the operation of sensors, led to a great extent by how they are exploited (setting / adjusting, installation and use), function dictates the optimal parameters of an industrial process. This paper aims to highlight the four categories of industrial sensors, their results after testing. For all 4 types of sensors have been carried out tests on a bench test equipment and sensors aimed mainly to the conditions imposed by the manufacturer on the installation setting / adjustment and use. Finally, results from testing were compared with those in data sheet.

Keywords:sensors, testing, detection, graphic
\end{abstract}

\section{INTRODUCTION}

Testing was carried sensors for monitoring of the technical chart them for different types of bodies, when they are detected.

Stand the structure of the sitting of a large number of sensors, with different ways of fixing. In figures $1,2,3$ and 4 are shown four different types of mounting the sensors on stand structure.

Depending on sensor type tested (capacitive, photoelectric color, inductive or vision) and the specific characteristics of each type of sensor in hand, after appropriate testing can be drawn graphics maximum detection distances for different body types, graphics of detection on $\mathrm{X}$ axis and $\mathrm{Y}$-report may show the behavior of sensors to detect bodies for different speeds.

Fitting the sensors to application specific mechanical structure that is integrated according to sensor type [6].

This color sensor (fig. 1) is done by setting side by two screws.

Capacitive sensor (fig. 2) is positioned through a specific support that comes with the sensor, and fixation is achieved by means of two screws on top of it.

Inductive sensor (fig. 3) is positioned in the same manner as capacitive, the difference being the fixing. Outer cylindrical surface of the inductive sensor is threaded, this facilitates fixation.

Vision sensor (fig. 4) is composed of two elements: the sensor itself to be fixed at the optimal distance from the objects detected and the touch finder, fixed in order to allow setting and reading data.

In parallel with the vision sensor is used another type of sensor that triggers image capture at a time.

\section{EXPERIMENTAL EQUIPMENT}

Analysis performed on the types of test stands for sensors, watching showed a very limited presence in the territory ofbussines and university.

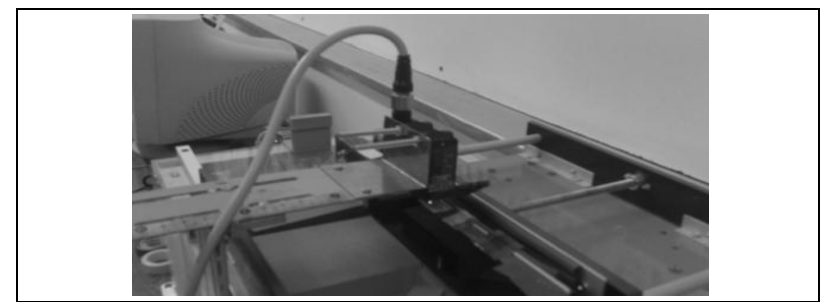

Fig. 1. Color sensor positioning

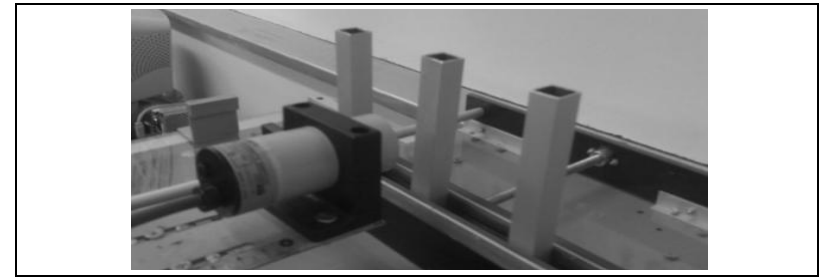

Fig. 2. Capacitive sensor positioning

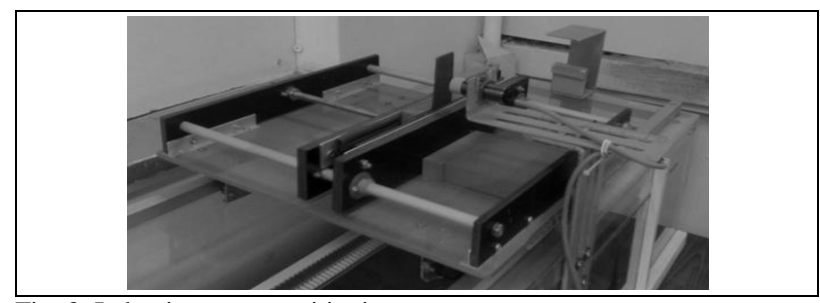

Fig. 3. Inductiv sensor positioning

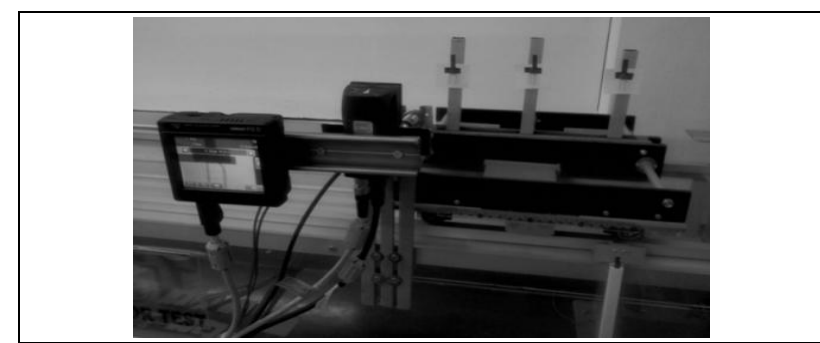

Fig. 4. Visionsensorpositioning

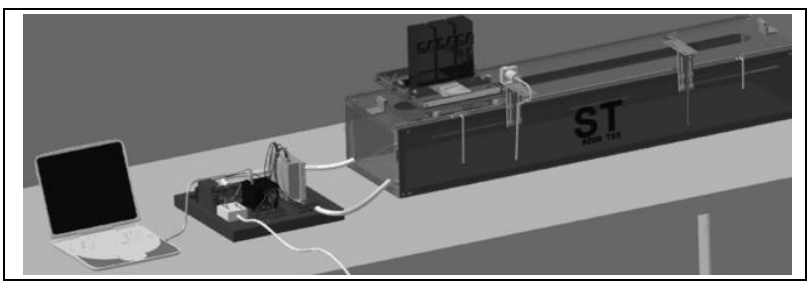

Fig. 5. Testing stand 
In this context, because the price of a modular test sensors and transducers were too high, for reasons of efficiency and flexibility to achieve this by purchasing preferred components from various suppliers and systems integration through or connecting elements and / or interface (fig. 5).

The mechanicalstand sensorstest [1], consists of three main assemblies:

a.The frame.

b.Transmission mode motion.

c.Pallet.

Pallet drive is via a toothed belt and toothed pulleys from a stepper motor. Motor control is made through a driver from the PLC.

\section{SETTING AND TESTING COLOR SENSOR}

Photoelectric color sensor used for testing [5] has the following features:

a. The detection distance is $10 \pm 3 \mathrm{~mm}$.

b.Incandescent light: 3,000 lux maximum.

c.Sunlight: 10,000 lux max.

d.Light source: LED green.

e. The supply is made from a 24 VDC power supply.

Color sensor can be used in two ways: to detect a color or to detect a color on a background color. The sensor data sheet are given colors it is not detected correctly.

Testing was conducted to highlight practical detection range of colors that can be achieved. Depending on the brightness and the distance between sensor and object for color identification is desired to obtain different results for the same shades of colors.

Learning a white symbol on a blue background (fig. 6 ) is accomplished using the following procedure:

a. Wide positioned so that the green area of the sensor to fall on white, then press the TEACH button and then press SET.

b.If learning is successful color, moving range, so that green light beam falling on the blue background and press the SET button again.

c. If the background learning is successful, it passes into how ADJ to adjust the threshold so that the incidence in the transition from blue to the white simbol background to be level or above the threshold.

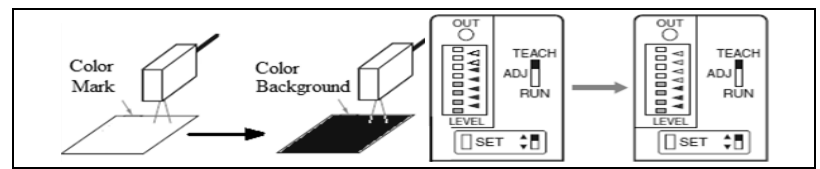

Fig. 6. Set the color sensor for learning

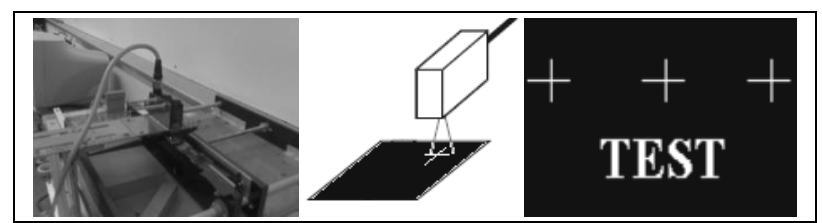

Fig. 7. Testing the actual color sensor
After setting operation of the sensor was moved to testing (fig. 7). We used several couples of color and noted that the color blue on white marking correct learning is repeating the steps several times before the learning procedure.

Connect the sensor and the driving motor of mobile sled to the PLC was achieved as planned in figure 8 .

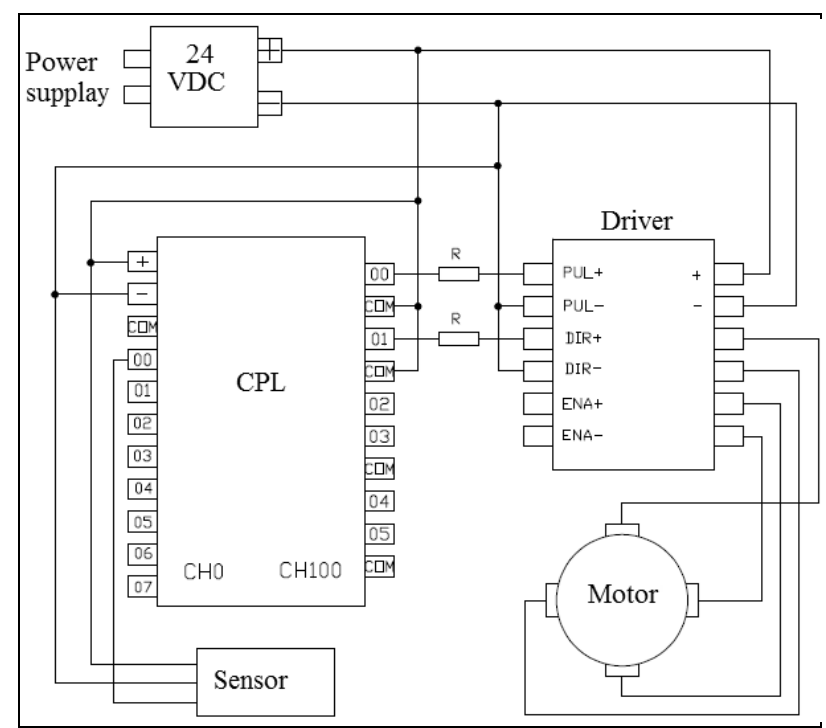

Fig.8. Connect the motor and sensor to the PLC

\section{TESTING CAPACITIVE SENSOR}

Capacitive sensor used for testing [3] has the following features:

a. Detect any material.

b. Detection distance is $25 \mathrm{~mm}$.

c. Detection distance can be adjusted between 3 and 25 mm.

d.the supply is made from a 24 VDC power supply.

e.type is PNP output.

f.The exterior dimensions of Ø34 x $82 \mathrm{~mm}$.

Connect the sensor to the PLC was made by the same circuit diagram presented photoelectric sensor (Fig. 8).

Graphs drawn after testing capacitive sensor are:

a. Graphic material / distance detection.

b. Detection distance axis $\mathrm{X}$-detection distance axis $\mathrm{Y}$.

For drawing graphs, data were obtained from experiments that were conducted after certain procedures, imposed after several tests.

Testing for graph drawing material / distance detection was performed using a series of materials with different densities.

In figure 9 are given some examples of materials used for testing, namely: water bottle, oil bottle, package of flour, sugar pack, aluminum bar and steel bar.

Different materials were chosen to test the sensor, so that it highlighted the operation for a wide range of objects / materials. 


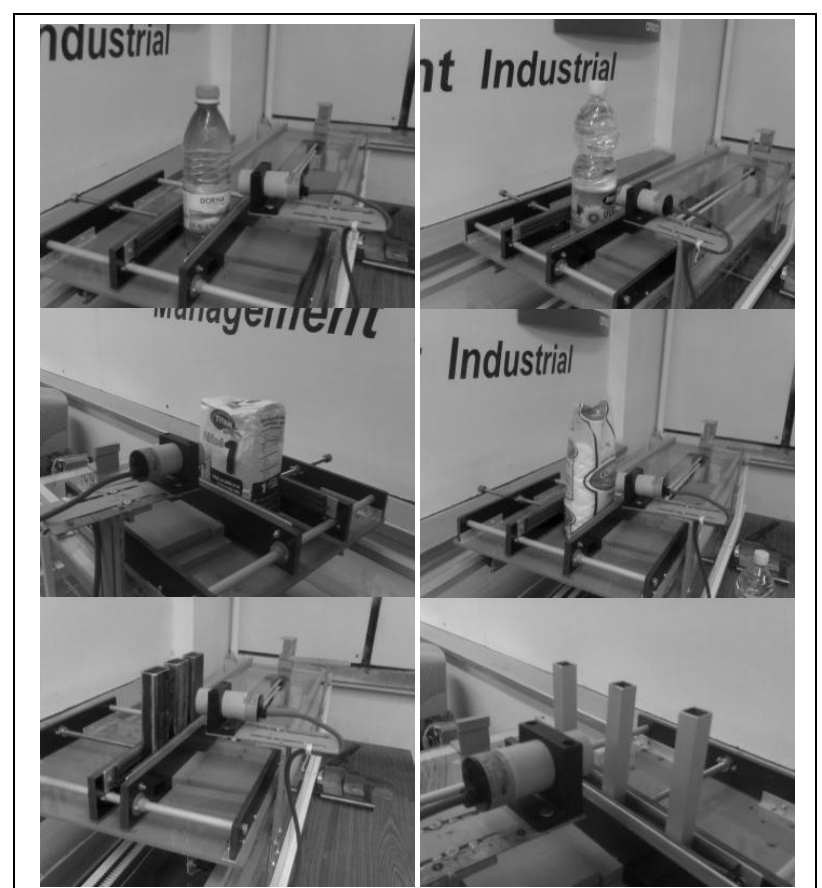

Fig. 9. Example of materials / objects used for testing

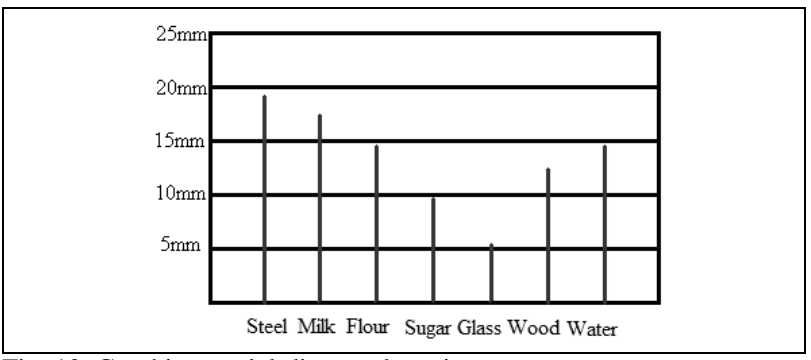

Fig. 10. Graphicmaterial-distancedetection

The data obtained are presented in Table 1.

\begin{tabular}{|c|c|c|c|c|}
\hline Material & Water & Steel & Milk & Flour \\
\hline Distance & $14.5 \mathrm{~mm}$ & $19 \mathrm{~mm}$ & $17 \mathrm{~mm}$ & $14.5 \mathrm{~mm}$ \\
\hline Material & Sugar & Glass & Lemn & Wood \\
\hline Distance & $10 \mathrm{~mm}$ & $6 \mathrm{~mm}$ & $12 \mathrm{~mm}$ & \\
\hline
\end{tabular}

Tab. 1. Experimental datafor thechart material testing capacitive sensordistance detection

Graph drawn for the values obtained (fig. 10) was compared with the pattern of data sheet. They found small differences that occurred for the following reasons: read error values for the two rulers graduated positioning error, the density of materials used was different from the materials data sheet.

Character of the chart made with experimental data obtained from testing, is very close to the graph of the data sheet were repeated tests thus obtaining values very close to those presented in data sheet.

Experimental data obtained from testing for trace detection distance graph axis $\mathrm{X}-\mathrm{Y}$ axis detection distance (fig. 11) are presented in Table 2.

For testing material used was steel in the form of rectangular profile.

\begin{tabular}{|l|l|l|l|}
\hline X-axis distance & $\mathrm{x}=0$ & $\mathrm{x}=1$ & $\mathrm{x}=2$ \\
\hline Y-axis distance & $\mathrm{y}=-20$ & $\mathrm{y}=-19$ & $\mathrm{y}=-17.5$ \\
\hline X-axis distance & $\mathrm{x}=3$ & $\mathrm{x}=4$ & $\mathrm{x}=5$ \\
\hline Y-axis distance & $\mathrm{y}=-16$ & $\mathrm{y}=-14.5$ & $\mathrm{y}=-20$ \\
\hline
\end{tabular}

Tab. 2. Experimental data testing capacitive sensor for remote detection chart axis $\mathrm{X}$-Yaxis detection distance
After drawing the graph distance detection axis $\mathrm{X}-\mathrm{Y}$ axis detection distance (fig. 12) could obviously limited, yet form field detection.

But how detection can be influenced by this object around the sensor (other than those to be detected) and that at a distance less than the manufacturer specified in the sheet

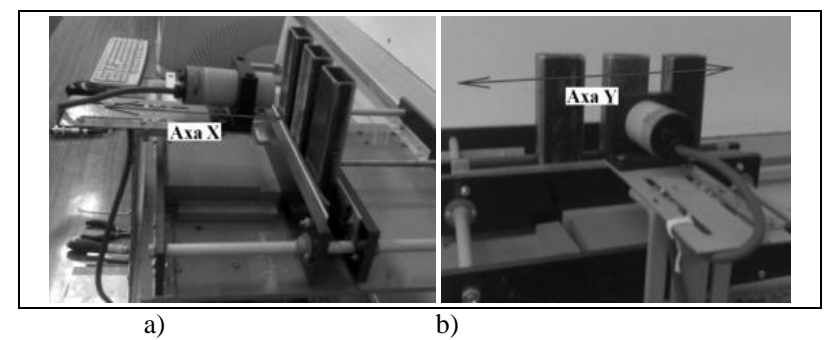

Fig. 11. Representingthe two axes: $\mathrm{a}-\mathrm{X}$ axis, $\mathrm{b}-\mathrm{Y}$ axis

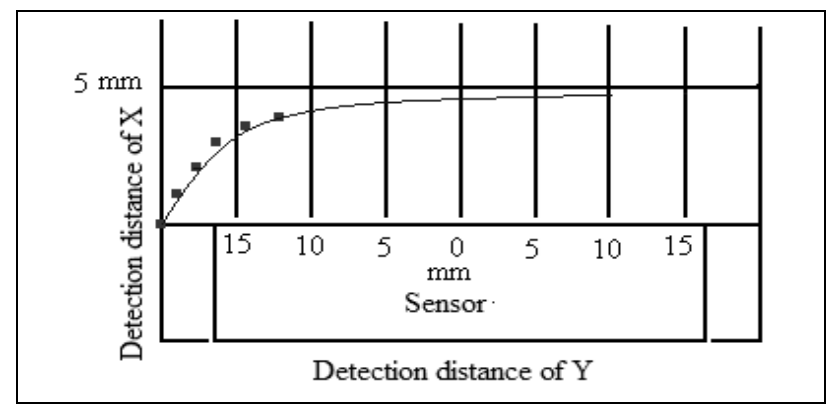

Fig. 12. Graphic distance detection axisX-Yaxis detection distance

\section{TESTING INDUCTIVE SENSOR}

Capacitive sensor used for testing [4] has the following features:

a.Detect ferrous metals, for non-ferrous metals the sensitivity decreases.

b. Detection distance is $8 \mathrm{~mm}$.

c. The supply is made from a 24 VDC power supply.

d. Type is PNP output.

e.M18 x $55 \mathrm{~mm}$ dimensions.

Connect the sensor to the PLC was made by the same circuit diagram presented photoelectric sensor (fig. 8).

Graphs drawn after testing inductive sensor are:

a. Graphic material / distance detection

b. Detection distance axis X - Y axis detection distance

Since inductive position sensor is performed similarly to the capacitive sensor, mode is similar to drawing the first two graphs.

Materials used for plotting the graph material distance detection are: steel, aluminum, copper, brass.

Values obtained from inductiv sensor testing was centralized in Table 3 .

\begin{tabular}{|c|c|c|c|c|}
\hline Material & Steel & Aluminum & Copper & Brass \\
\hline Distance & $7.5 \mathrm{~mm}$ & $4 \mathrm{~mm}$ & $3.5 \mathrm{~mm}$ & $3 \mathrm{~mm}$ \\
\hline
\end{tabular}
Tab. 3. Experimental data for the chart material testing inductive sensor
- distance detection

Graph drawn with the values obtained (fig. 13) illustrates that for ferrous materials detection distance decreases.

In the case of the inductive sensor metalic materials around can influence the detection mode and thus it is 
important that the producer's standards to be followed. Experimentally it was established that if this requirements aren't met the sensor won't function properly.

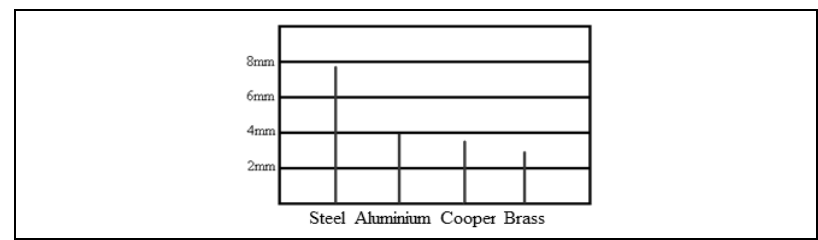

Fig. 13. Graphic material - distance detection

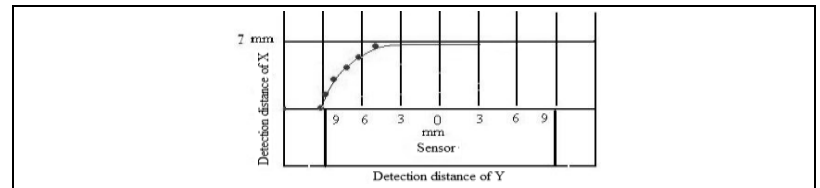

Fig. 14. Graphic distance detection axisX-Yaxis detection distance

\begin{tabular}{|c|c|c|c|}
\hline X-axis distance & $\mathrm{x} 1=0 \mathrm{~mm}$ & $\mathrm{x} 2=1 \mathrm{~mm}$ & $\mathrm{x} 3=2 \mathrm{~mm}$ \\
\hline Y-axis distance & $\mathrm{y} 1=9.5 \mathrm{~mm}$ & $\mathrm{y} 2=9 \mathrm{~mm}$ & $\mathrm{y} 3=8 \mathrm{~mm}$ \\
\hline X-axis distance & $\mathrm{x} 4=4 \mathrm{~mm}$ & $\mathrm{x} 5=5 \mathrm{~mm}$ & $\mathrm{x} 6=6 \mathrm{~mm}$ \\
\hline Y-axis distance & $\mathrm{y} 4=7 \mathrm{~mm}$ & $\mathrm{y} 5=6 \mathrm{~mm}$ & $\mathrm{y} 6=4 \mathrm{~mm}$ \\
\hline
\end{tabular}

Tab. 4. Experimental data testing inductive sensor for remot edetection chartaxis $\mathrm{X}-\mathrm{Y}$ axis detection distance

And for inductiv esensor detection distance by drawing grapha xisX-Yaxis detection distance (Fig. 14)could obviously limited, yet form field detection.

\section{SETTING AND TESTING VISION SENSOR}

Vision sensor [2] allows testing several types of inspections (Table 5), the results are presented only for inspection experimental type search form.

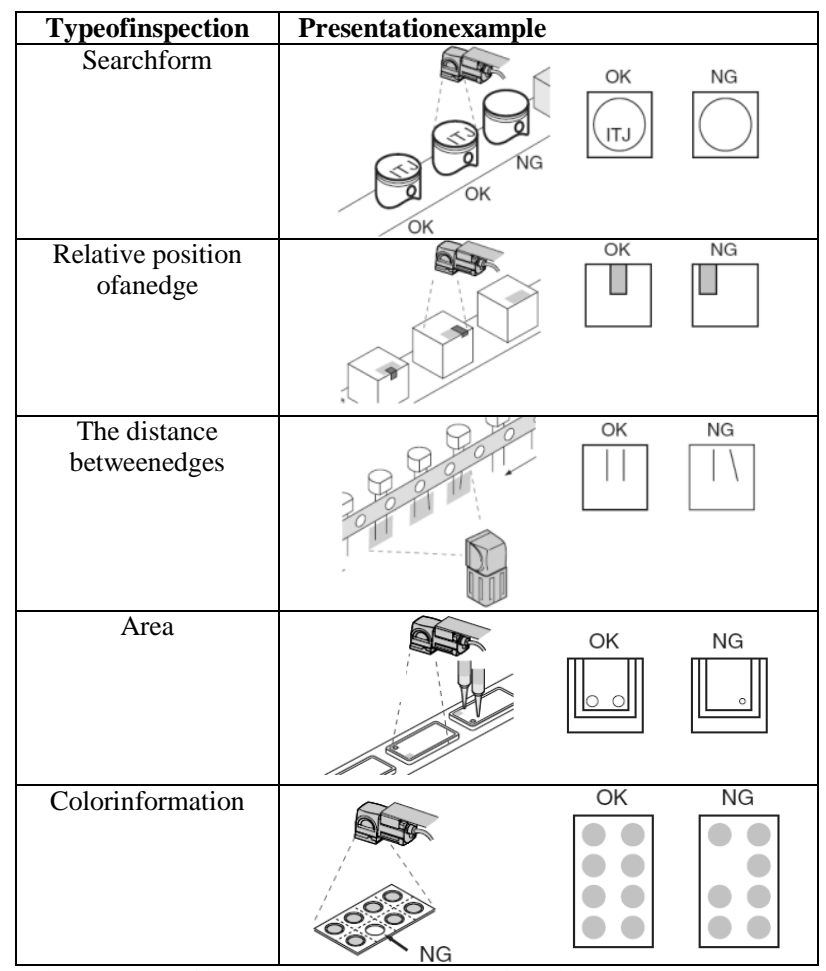

Tab. 5. Types of inspections that can be achieved by vision sensor

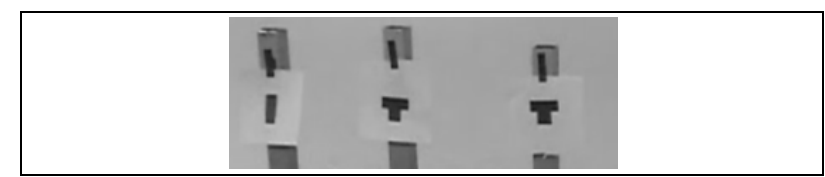

Fig. 15. Forms used for inspection of such search form

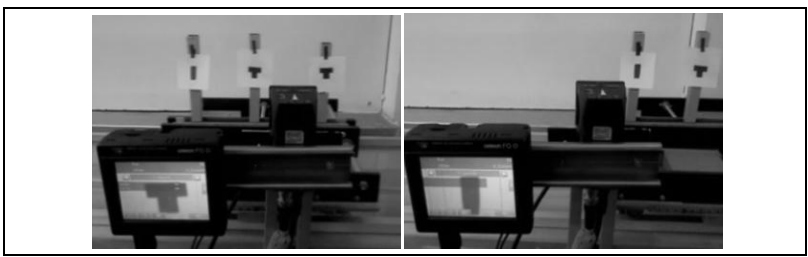

Fig. 16. Type of in spection results search form

Standard procedure to be followed for setting sensor is: Setting the type of inspection - Learning - Setting parameters for a decision - Setting-Relearn details. For inspection forms [] were used as shown in figure 15. In the first image in figure 16 the result is validated as being taught that when they realized settings. For the second image in figure 16 sensor sends a signal indicating that the shape does not correspond to form learned.

\section{CONCLUSION}

Regardless of sensor type used, its position in relation to items that are to detect / inspect, is very important.

Inductive and capacitive sensors for the installation must take into account the influence of surrounding materials.

For photoelectric sensors and vision must be taken into account when exploiting the light intensity does not change, this led to incorrect operation and the necessity to reconstruct the sensor settings.

Inspection results for vision sensor are the same even if the forms used to change position.

In future sensors with high precision will be tested in order to set the issues that may appear when they are positioned and operating.

\section{ACKNOWLEDGEMENTS}

The work has been funded by the Sectoral Operational Programme Human Resources Development 2007-2013 of the Romanian Ministry of Labour, Family and Social Protection through the Financial Agreement POSDRU/107/1.5/S/76903.

\section{REFERENCES}

[1] George Enciu, Adrian Popescu, (2011). Researching and achievement of a sensor testing stand, Proceedings in Manufacturing Systems, Volume 6, Issue 4, ISSN 2067-9238, Bucharest

[2] http://ia.omron.com/product/family/2956/index_fea.html, (2011), Sensor vision, Accessedon: 2011-11-10

[3] http://ia.omron.com/product/family/470/index_fea.html, (2010), Capacitive sensor, Accessed on: 2010-12-08

[4] http://ia.omron.com/product/family/449/index_fea.html,

[5] (2010), Inductive sensor, Accessed on: 2010-10-11

[6] http://ia.omron.com/product/18.html,(2011), Color sensor, Accessed on: 2010-03-07

[7] George Enciu (2011). Logistica Intreprinderilor Industriale, Fair Partners, ISBN 978-973-1877-53-2, Bucuresti 